\title{
The role as moderator and mediator in parent education groups - a leadership and teaching approach model from a parent perspective
}

\author{
Karin Forslund Frykedal and Michael Rosander
}

Linköping University Post Print

Tweet

N.B.: When citing this work, cite the original article.

Original Publication:

Karin Forslund Frykedal and Michael Rosander, The role as moderator and mediator in parent education groups - a leadership and teaching approach model from a parent perspective, 2015, Journal of Clinical Nursing.

http://dx.doi.org/10.1111/jocn.12856

Copyright: Wiley: 12 months

http://eu.wiley.com/WileyCDA/

Postprint available at: Linköping University Electronic Press

http://urn.kb.se/resolve?urn=urn:nbn:se:liu:diva-118118 


\title{
The role as moderator and mediator in parent education groups - a leadership and teaching approach model from a parent perspective
}

\author{
Karin Forslund Frykedal and Michael Rosander
}

Karin Forslund Frykedal, PhD, Senior Lecturer, Department of Behavioural Sciences and Learning, Linköping University, Linköping

Michael Rosander, $\mathrm{PhD}$, Associate Professor of Psychology, Department of Behavioural Sciences and Learning, Linköping University, Linköping, Sweden

Published in Journal of Clinical Nursing, doi: 10.1111/jocn.12856

Accepted for publication: 17 March 2015

\begin{abstract}
Aims and objectives. To investigate the didactic and social leadership in parent education groups based on a parent perspective, and to conceptualize parent experiences of the leader roles in these groups.
\end{abstract}

Background. Leadership in parent education groups has been associated with a lack of confidence in one's ability to function in that role. Research on how it can be delivered to produce a favourable outcome is scarce. It can be difficult to abandon the role of expert and let participants set their own learning agenda. To facilitate these processes requires leadership skills, knowledge of group dynamics, as well as pedagogical skills.

Design. Qualitative interview study.

Methods. Semi-structured interviews with parents (25 participants, 21 interviews). Transcripts were analysed using, first, thematic analysis, then comparative analysis.

Results. The study resulted in a four-field model, The Leadership - Teaching Approach model. It consists of the dimensions "Teaching approaches" ("Knowledge is imparted" and "Knowledge is jointly constructed "), and "Leadership approaches" ("Instrumental approach" and "Investigative approach").

Conclusions. Using an investigative approach is necessary in order to get a well-functioning group that can help the expectant and new parents in the transition to parenthood. Supervision can help develop an awareness of one's professional role as a nurse and leader of a parent education group.

Relevance to clinical practice. The actions and choices of nurses as leaders of parent groups have an impact on how the participants perceive and take in the content and purpose of the group, and whether they perceive it as meaningful. Getting support in reflecting about one's role as a leader in this context can help create a learning environment in which the participants can become engaged in the activities and be strengthened by the experience.

\section{What does this paper contribute to the wider global clinical community?}

- A parent (patient) perspective on method of delivery and leadership approach when working with groups in primary care.

- A model, which conceptualizes the didactic and social leadership in parent education groups, and is also transferable to other areas in primary care where patient groups are being used.

Keywords: Education, Interviews, Leadership, Nurse roles, Parenting, Qualitative research 


\section{INTRODUCTION}

Leadership in parent education (PE) groups is often associated with a lack of confidence in one's ability to function in that role (Barlow et al. 2009). There is a body of evidence around what content should be communicated (Nolan 2009), but research on how it should be implemented in the group is scarce (Barlow et al. 2009, Thielen 2012). Research has often focused on the outcome of PE, such as how antenatal education has helped mothers with handling childbirth and pain, rather than the process (Fabian et al. 2006, Gagnon \& Sandall 2007, Bryanton et al. 2013). Parents want leaders who can create interactive and participative learning environments instead of a more directive or lecture type of approach (Petersson et al. 2004, Schrader McMillan et al. 2009, Andersson et al. 2012). As a leader it can be difficult to abandon the role of expert and let the participants be part of and set their own learning agendas (Nolan 2009, Schrader McMillan et al. 2009, Lefèvre et al. 2013). To be able to facilitate these processes requires leadership skills and knowledge of group dynamics as well as pedagogical skills (Andersson et al. 2012). However, there is a lack of specialised training in these areas, and also a lack of support for those providing the services (Ahldén et al. 2008, Barlow et al. 2009, Lefèvre et al. 2013). Wiener and Rogers (2008) specifically suggested group facilitation training to be an integral part of the basic training for midwives. There is "a need to build midwife confidence and skills in its delivery" (Barlow et al. 2009, p. 4).

Parents do not attend PE groups only to receive information and to develop skills, but also to meet other parents (Nolan 2009, Murphy Tighe 2010, Norling-Gustafsson et al. 2011). The group can become a forum for sharing experiences and help parents normalize and defuse pregnancy and delivery (Wiener \& Rogers 2008, Andersson et al. 2012). If opportunities to socialize are not provided, the whole class can be perceived as unsatisfactory by the parents (Nolan 2009). The group can also be a means to ease the transition into parenthood something PE often fails to prepare parents for (Deave et al. 2008, Barlow et al. 2009). In Sweden PE groups continue after the perinatal period. Sometimes the same group stays together throughout pregnancy and early parenthood (up to about one year after childbirth), but in most cases nurses in child health care create new groups of parents with newly born children and take over the role of providers of PE from the midwives in antenatal care (Fabian et al. 2006). Most expectant and new parents who attend primary health care in Sweden are offered PE in groups with a focus on enhancing competence and coping as parents, and to help create networks between parents (Sundelin \& Håkansson 2000, Lefèvre et al. 2013, 2014). In this study there is a focus on the leadership role in PE groups. The leaders could be either midwives in antenatal care or nurses in child health care; hereafter we will refer to both as leaders because it is not so much the leader's profession as it is the processes of these groups that are in focus.

\section{BACKGROUND}

\section{Group education in primary health care}

In the context of primary health care, the term 'group education' is often used for any forms of education aimed at a group. Group education can provide for extensive parent participation (Sahlsten et al. 2008). Participation in this context involves for the leader to leave some of the control to the group and provide opportunities to share information and knowledge in an active engagement (Sahlsten et al. 2008). 
Studies on group education within primary health care typically lack information about the pedagogical principles used or what type of knowledge is expected as outcome. Competence such as parental competence is mainly experience-based knowledge (Kolb 2014). Such competence relates to an active learner and is based on individuals' capacity to combine life events with theoretical knowledge in their interaction with others, and is not taught via direct instructions or learned in top-down educational relations (Boud et al. 2001, Dornan et al. 2007). Through interaction, group members can learn to share ideas and construct new understandings. A great advantage of group collaboration is the scaffolding process whereby group members act as resources for each other and help each other progress. Peer group learning is a pedagogical method (Boud et al. 2001, Secomb 2008), which may create a learning environment, where group members are active participants. This is opposed to a 'topdown' approach where they passively listen to an expert.

\section{The group leader}

Group leaders can either actively convey knowledge to other group members as mediators, or moderate more interactive processes to facilitate interaction between group members. This may include sharing experiences and discussions with the leader as moderator (Hoddinott et al. 2010). These two different roles are based on different theories of learning. One is social cognitive learning theory (Bandura 1976), in which the individual learns by observing and imitating a role model. The other is social constructivist theory (Vygotsky 1978), in which learning takes place in interaction and communication with the social environment and the people included in it.

Group education leaders have an effect on how groups function (Gillies 2003) both in a didactic and social perspective. A group leader can help create a level of intragroup trust important for both the emotional climate and group performance (Simons \& Peterson 2000). From an organisational viewpoint, the decision to use groups is often guided by economical principles and groups are considered just a collection of individuals. However, without considering pedagogical and psychological aspects, the potential for cost effectiveness using groups compared to individual treatment is mixed and often weak (Hoddinott et al. 2010). In contrast, if you allow a group to work in a way which is characterised by efforts to utilize the group's competences and resources, it has a much greater potential for positively influencing the group members because being in a group environment allows individuals to draw on and learn from each other (Jarvis et al. 2010).

\section{The aim of the study}

The aim of this study was to investigate the didactic and social leadership in parent education groups based on a parent perspective, and to conceptualize parent experiences of the leader roles in these groups.

\section{METHODS}

\section{Design}

The data consisted of 21 semi-structured interviews with parents. Four researchers, including the two authors, conducted the interviews based on a common interview guide consisting of questions in three areas: (a) the parent education, (b) the leader of the PE group, and (c) the PE group. The interviews were conducted in various places depending on the wishes of the parents interviewed (at the university, at open preschools or child care centres, or in the homes of participants). All interviews were carried out in closed offices or the equivalent. The 
interviews lasted between 13 minutes and 54 minutes, giving a total of 685 minutes of recorded interviews. All interviews were transcribed verbatim followed by a three-part analysis. In the first two parts thematic analysis was used, which is a stepwise process with clear guidelines aimed to create themes (Braun \& Clarke 2006). In the third analytic step comparative analysis inspired by Strauss and Corbin (1998) was used to find relationships between the themes. The study was approved by the regional Research and Ethics Committee at Linköping University, Sweden.

\section{Data collection}

Participants were recruited through several Child health care units, and a targeted selection was used which required participants to have had recent experience (2 years or less since completion) of attending some form of PE group. A total of 25 individuals were interviewed (20 mothers and 5 fathers). Seventeen of the interviews were one-to-one interviews and four had both parents present. The participants' ages varied from 23-42 years. 20 of the participants were born in Sweden and 5 had other ethnicity. About half of the participants were from big cities and half from small towns. Informed written consent was obtained from all participants.

\section{Data analysis}

The two authors conducted the first step of the analysis separately using MAXQDA11 (software, MAXQDA 2014) collating data relevant to each code with a focus on the parents' perceptions of the leadership, the group, the content and learning methods, and the parents' opportunities to influence. A large number of codes were created. The second step involved both authors in a common analysis process of collating codes into eight themes and to refine the specifics of each theme. In the third step of the analysis the themes were compared and sorted in a comparative analysis, conducted by the two authors together, to search for relations between the themes. Two approaches were formed, which became the basis for the construction of two models.

\section{RESULTS}

Eight themes were created in the second step of the analysis: (a) controlling the content, (b) presence, (c) responsiveness (d) leader's competence, (e) attitude, (f) normative or critical approach, (g) engagement, and (h) providing security. From this, in the third step of the analysis, two approaches were formed - Teaching approaches and Leadership approaches. Teaching approaches is divided into two aspects: "Knowledge is imparted" and "Knowledge is jointly constructed". In the dimension Leadership approaches the two aspects are named "Instrumental approach" and "Investigative approach".

\section{Teaching approaches}

A teaching approach is about how the subject matter (e.g., pregnancy, childbirth, breastfeeding, and child development) is dealt with in the PE group in order to enable parents to obtain knowledge and learn. According to the parents this is done primarily through lectures, group discussions, film screenings, and skills training. When it comes to the teaching approach the parents described two general ways, in which this is done: (a) knowledge is imparted by the leader to the parents primarily through lectures, and (b) knowledge is jointly constructed in group discussions in the PE group, and between the leader and parents in conversations and discussions. 
In most cases the leaders have a manual for support in the planning and execution of the PE group. The manual commonly contains information about the goals of PE, what the content for specific group sessions should cover, and what skills and experiences should be dealt with. It can also provide suggestions of specific questions that can be used to help start group conversations, as well as descriptions of tasks appropriate to structure group meetings. Many of the leaders have had previous experiences from conducting PE groups as well as their own knowledge and expertise in the subjects, which are covered in the PE group. The information from the manual, their previous experience, and their knowledge and skills in the relevant field are the three common starting points that leaders use when they plan and execute PE groups.

\section{Leadership approaches}

A leadership approach is about how one, more or less consciously, relates to someone or something, and uses this as a starting point for action in the current situation. The leadership approach influences the leader role and how the leader will interact with the PE group. From the interviews two general approaches emerged: (a) an instrumental approach, and (b) an investigative approach.

In the instrumental approach a manual is normally used by the leader when planning and conducting a PE group, along with their previous experience and knowledge in the field. In the instrumental approach the reason why a specific content is addressed in the group is not linked to the specific group. Instead, the manual and/or the leader's experience of previous PE group are used as a guide without further reflection.

In the investigative approach, a manual can be used as a guide together with prior experience, but the difference is that they are used in a more conscious manner as a guide along with considering the current group's circumstances, expectations, and needs. Such awareness means that the leader can adapt the work based on the objectives, relevant parts of the manual, and their own knowledge and experience as well as considering the needs of the current group.

A four-field model was created based on these two dimensions, Leadership approaches and Teaching approaches (the LTA model), and their respective aspects (see Figure 1). More than one or all four of these approaches can occur in a single PE group, and they can be fully relevant choices for leaders at different stages of a PE group. These four fields are clarified below. The model, its dimensions, and the content are dynamic in the sense that both leadership and teaching approaches may vary depending on the context.

\section{The instrumental approach (Field $A$ and $B$ )}

With the instrumental approach, a manual, the leader's previous experience and/or knowledge dictates whether subject matter should be imparted or jointly constructed. This is done without any regard to the group's circumstances, needs, or expectations. The PE group is carried out without any conscious adaptation to the specific group or context.

She had an agenda from the start which was good so I definitely cannot complain about it, it's just that she could have been open from the beginning that 'this and this, we must cover this material and if you have any further questions we will try to discuss it if I think it is relevant'. (Int15) 


\begin{tabular}{|c|c|c|c|}
\hline & & \multicolumn{2}{|c|}{ Teaching approaches } \\
\hline & & Knowledge is imparted & Knowledge is jointly constructed \\
\hline \multirow{2}{*}{ 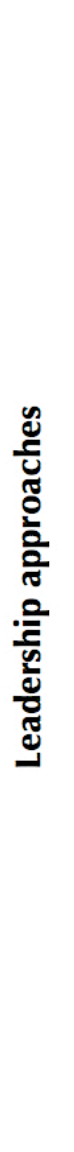 } & $\begin{array}{r}\text { Instrumental } \\
\text { approach }\end{array}$ & $\begin{array}{c}\text { A } \\
\text { Following a manual } \\
\text { - Based on it, this particular } \\
\text { information should be imparted } \\
\text { Following one's previous } \\
\text { experience and/or knowledge } \\
\text { - I tend to impart } \\
\text { this particular information } \\
\text { Not trying to take the group's } \\
\text { expectations and/or needs into } \\
\text { account }\end{array}$ & $\begin{array}{c}\text { B } \\
\text { Following a manual } \\
\text { - Based on it, the group should } \\
\text { work with this particular content } \\
\text { Following own previous } \\
\text { experience } \\
\text { - I usually use group work } \\
\text { for this particular content } \\
\text { Not trying to take the group's } \\
\text { expectations and/or needs into } \\
\text { account }\end{array}$ \\
\hline & $\begin{array}{r}\text { Investigative } \\
\text { approach }\end{array}$ & $\begin{array}{l}\text { C } \\
\text { To examine and decide for this } \\
\text { particular content - in relation to the } \\
\text { manual, one's experience and/or } \\
\text { knowledge, and the current group's } \\
\text { circumstances, expectations and } \\
\text { needs - that learning will benefit if } \\
\text { knowledge is imparted } \\
\text { Trying to take the group's } \\
\text { expectations and/or needs into } \\
\text { account }\end{array}$ & $\begin{array}{l}\text { D } \\
\text { To examine and decide for this } \\
\text { particular content - in relation to the } \\
\text { manual, one's experience and/or } \\
\text { knowledge, and the current group's } \\
\text { circumstances, expectations and } \\
\text { needs - that learning will benefit if } \\
\text { knowledge is jointly constructed } \\
\text { Trying to take the group's } \\
\text { expectations and/or needs into } \\
\text { account }\end{array}$ \\
\hline
\end{tabular}

Figure 1. The Leadership - Teaching Approach model (LTA model).

If imparted the leader presents the material through lecturing to the parents and the material is chosen through what the leader feels is important information to convey. The chosen material is supported by the manual and the leader's prior experience and personal knowledge. The leader takes on the role of an expert and a mediator. This does not leave much room for the parents to discuss the material among themselves or in smaller groups.

We did not talk much with the other couples. There was a lot of information from the midwife, and then our two hours had passed and then we had some coffee and then it was time to go home.

(Int20)

The leader can also initiate conversations and discussions in the large group or in smaller group formations, and can choose to take part in the discussions or leave it up to the group to keep the discussions going. The leader can take on the role of an expert, but also as a moderator. No matter which role they choose, it is done without much reflection and is often based on what the manual or previous practice suggests. 
It was like, now you're going to discuss this and you go to the group and then we sat there and stared at each other. We did not get any further because there was no one who took the lead, so we sat in a room staring. (Int21)

When the leader leaves the group alone without first implementing any structure to continue group discussion the parents feel that the PE group fails. How the leader chooses to use the manual can also strongly influence how the PE groups are perceived. By giving the group a task in which they construct questions in smaller groups, but then not follow up these questions in favour of continuing on the agenda, the leader creates an illusion of participation.

\section{The investigative approach (Field $\mathrm{C}$ and $\mathrm{D})$}

If the leader chooses to use an investigative approach, this means they will examine and take the prerequisites, expectations and needs of both the individuals and the group as a whole into consideration when designing the structure of the group.

She asked us what we were wondering about the most and engaged us in the educational process by making us parents the focus and taking up what we thought was important. (Int6)

The leader has a focus on the current group, and with support from the manual, and previous experience and knowledge, the leader is able to adjust the planning and execution of the PE group with a more conscious pedagogical strategy. Consequently, the role of the leader may be that of an expert, although the decision to impart knowledge is grounded in at least an attempt to examine the expectations and needs of the current group and the context.

In an investigative approach the leader and parents can also work with the content together through group discussions - as a whole group or in smaller groups. The leader's primary role is to challenge, problematize and help the group further develop the content themselves. Even though the leader is not present in every group, tasks and issues that the groups can work with have been planned based on the current group's needs and circumstances.

We thought it was great fun to be there because we were eight completely different personalities, and [the leader] became the link that made us open up at those meetings. (Int10)

The leader can influence the group to open up through creating an open climate in the group and fostering conditions to get the group to work together and construct knowledge based on the leader's competence as well as the thoughts and experiences within the group.

\section{Responsiveness as a tool}

An investigative approach requires some form of responsiveness from the leader towards the group. Responsiveness can involve examining expectations on the PE group and the leader, but also trying to find the group members' needs, finding the right level of communication and tasks for the group, as well as responding to the group's questions. Being responsive to the group's needs and issues is important for the interaction between the leader and the parents, and creates conditions for a well-functioning group.

Examining expectations and needs. Group members come into the group with different expectations of what the PE group can provide and how it should be implemented, and on the leader, as well as the structure of various activities, for example that you will get to interact with the whole group and perhaps in smaller groups. 
She spent a lot of time instructing the group. We would have liked to engage more in discussion groups too. She probably should have taken a step back and let the parents discuss issues in small groups. (Int20)

A group can become a sounding board where parents can get confirmation that what they do is ok, or that their child's development or behaviour is similar to what the other parents describe. However, there are also examples of other, opposite expectations, where the leader is expected to take on an expert role with the group just passively listening.

I wished that she had been more directive, and talked more herself, giving information and such. (Int2)

Different group members from a single group may have different expectations on the leader either to lecture more or to express different perspectives and problematize - and different needs. The challenge is to bring together these different expectations and needs, and use them as a basis for the teaching approach.

Knowing how to respond to their various needs may mean that some content could be best managed through small group discussions, but the leader also has to be aware of some members' needs for security when dividing into smaller groups.

Being responsive to both the whole group and the individual parents means that a leader must be prepared to let go of some of the control of the content to the parents, but it can also become a burden for everyone involved if the leader has difficulty incorporating and prioritising different needs expressed in the group.

It was like she wanted everyone to be happy all the time, but she became very insecure instead. (Int5)

An ambition to make everyone happy and fulfil all wishes can backfire.

Find the right level for the group. Responsiveness can also be about finding the right level for the group. This means ensuring that everyone understands, but without necessarily spending too much time on the obvious.

She discussed things on a level that I felt I understood, and that's okay, we get it, us parents are new to all this. (Int9)

A leader has to be sensitive to how much support a group needs and how independent they can be. Furthermore, finding the right level for the group may be about deciding what content is appropriate. They must lecture at the right level for the group and decide if questions, instructions, and tasks are also at an appropriate level for the group to handle. This also includes an assessment of what role one should take on as a leader.

Relate to questions in the group. To be perceived as responsive by the parents, in many cases it may be enough to just answer the questions that come up. A prerequisite could be that the leader invites the group to ask questions. This may also positively influence the interaction process, and create a secure climate and a sense of cohesion in the group.

Because we think [the leader] is good we end up talking more. Then when we ask questions and we get answers it makes you - then you ask more questions. I felt a certain security in the group.(Int10) 
In the opposite case, not to answer the questions that come up creates frustration, especially if a leader has invited questions. This easily creates a belief that the leader is incompetent.

She listened to what we asked, but she did not answer the questions. She started talking about something else. (Int17)

In an investigative approach, it is important that the leader is able to make a reasonable judgement of when to take on an expert role and when to reflect back to the group, challenge the group and problematize. This allows the group to work together to construct knowledge together and this creates conditions for an integrative approach.

\section{The leader's roles in group-discussions}

Having group discussions means having a teaching approach in which knowledge is jointly constructed. The leader can be in the foreground or in the background, and may also be perceived as passive or active through their actions (see Figure 2). A passive leader can sometimes even leave the room and let the parents be on their own. An absent leader is something that affects the participants' experience of the leader's commitment.

She left during a film and then came back a little while later, when the film had long since finished.

She did not seem to be engaged with us. (Int2)

\begin{tabular}{c|c|c|c|} 
& In the foreground & In the background & Absent \\
\hline Active & $\begin{array}{c}\text { Takes on an expert role } \\
\text { Gives answers } \\
\begin{array}{c}\text { Provides discussion } \\
\text { structure (using an } \\
\text { instrumental or } \\
\text { investigative approach) }\end{array}\end{array}$ & $\begin{array}{c}\text { Challenges } \\
\text { Protivates }\end{array}$ & $\begin{array}{c}\text { Has left the room but has } \\
\text { provided the group with } \\
\text { appropriate tasks and } \\
\text { structure (using an } \\
\text { instrumental or } \\
\text { investigative approach) }\end{array}$ \\
\hline & - & $\begin{array}{c}\text { Sitting quietly } \\
\text { with the group }\end{array}$ & $\begin{array}{c}\text { Has left the room, leaving } \\
\text { to the group to provide } \\
\text { structure to the discussion }\end{array}$ \\
\hline
\end{tabular}

Figure 2. The leader's roles in group-discussions.

The leader may give the group a task, or a starting point for small group discussions, but then fails to support or help the group advance. Tasks based on an instrumental approach in which the group's expectations and/or needs are not taken into account leave to the group to provide a contextual structure to the discussions. This is something that is not easy to handle without support and can easily result in a passive group. To leave the group on their own but first provide tasks and structure for the group to work with (based on an investigative approach) provides opportunities for the group to construct knowledge together.

To be present but in the background can be perceived as passive, but also active. A passive leader may be perceived as insecure in one's role of working with groups. A passive leader mostly sits quietly with the group. 
The leader introduced herself and then just sat there on a sofa and did nothing. The mothers in the group talked, but that was about it. (Int17)

Being an active listener, although in the background, the leader can provide support for the group, ready to ask questions to promote the group work. This behaviour signals the leader's confidence in the group's competence.

She listened and put in a word sometimes 'yes, but what do you think about that?' We mostly did the talking, but she was there to give it structure and order. (Int7)

Leaders who are perceived as secure in their role and how they work with groups can encourage the group to open up and learn from the experience and knowledge that each member brings to the group. The leader's role here is to challenge parents and help problematize issues in the group.

An active leader can also put oneself in the foreground taking on an expert role when responding to questions that arise in group-discussions. In some cases the leader stays in the foreground and does not let the group participate at all, thus becoming passive recipients.

There were a lot of information, the midwife talked and talked, and then it was time to go home. (Int20)

The leader in this example probably feels secure about her knowledge in the field, but less secure on being a leader and working with the group.

\section{DISCUSSION}

This study shows the importance of taking a group's expectations and needs into account when planning and executing PE groups. The results show that group leaders work with PE groups and the content in different ways (Teacher approaches). They also focus on the group members' expectations and needs to varying degrees (Leadership approach). Previous studies on PE groups have had limited or no focus on the educational and group psychological aspects (Fabian et al. 2006, Gagnon \& Sandall 2007, Barlow et al. 2009, Thielen 2012). In this study, we contribute to these aspects by having constructed a model (the LTA model) to show how leaders use different teaching approaches and leadership approaches in the implementation of PE groups. The model is constructed using data from a Swedish context, but is applicable in an international setting. It is primarily aimed at PE groups, but is general enough to be used for patient groups in other areas within health care.

There is a lack of educational or leadership training for nurses (Ahldén et al. 2008, Barlow et al. 2009, Lefèvre et al. 2013). Some are probably well equipped to work with groups based on personal interest and ability, but in general there is a lack of systematic tools for leaders of PE groups. In this study, we contribute to mending the gap by presenting the LTA model. It can be used as a starting point for implementation as well as for reflection, and shows how a leader may act in terms of teaching approaches and leadership approaches, and how this can be used in interaction with the group. From the parents' perspective, it is important that the leader can respond to their expectations of what they think the PE group should contain and how it should be executed. At the same time the leader needs to direct the implementation to meet the objectives of PE. In the LTA model, a responsiveness to the group involves actions 
and behaviours primarily found in Field $\mathrm{C}$ and $\mathrm{D}$, which means that the leader will focus on examining and if possible meeting the parents' expectations. However, it is feasible to begin through implementing aspects of Field A or B for some parts of the PE group, which may be necessary in order to meet the objectives of PE. For this to be a viable option the leader should base the choice through considering a particular content in the context of the current group and not solely follow the manual or one's previous experience. Following a manual can both be an aid and a hindrance to the leader. Manuals can be viewed as a helpful tool for the leader to assist implementing the PE group, but it can also be prohibitive as it reduces the opportunity for the leader to organise learning and to create content that is customised for the current group. Without adequate training as a leader and a teacher it is all too easy to fall back on a manual without proper reflection. Leaders can evoke uncertainty and insecurity in a group through their actions, but can also, through their teaching approach and their leadership approach, have a great effect on intragroup trust (Simons \& Peterson 2000) and group security which can help the parents strengthen their new role as parents. One way to help leaders to develop self-awareness, that is needed to deal with these issues, is through group supervision. Severinsson et al. (2010) showed that midwives developed an awareness of their professional role by participating in group supervision, and this awareness is an essential aspect in order to develop group leadership skills.

\section{CONCLUSIONS}

The leader working with a PE group can choose to create a predominantly parent-centred learning environment or a more leader-centred one. Some content needs to be covered in PE groups connected to giving birth or becoming a new parent, but how it should be implemented is in many ways for the leader to decide. The two teaching approaches, i. e., when knowledge is imparted or jointly constructed, can be seen as different perspectives on how to learn - from passive to active learning. Using an investigative approach is necessary in order to get a well-functioning group that can help the expectant and new parents in the transition to parenthood. We believe that it is important that leaders become aware of different approaches to teaching when working with PE. This could be achieved by using, for instance, group supervision.

\section{RELEVANCE TO CLINICAL PRACTICE}

The actions and choices of nurses as leaders of PE groups, have an impact on how the participants perceive and process the content and purpose of the group, and whether they perceive it as meaningful. Getting support (for example supervision - between colleagues or in a group) in reflecting about one's leadership role in this context can make nurses more aware of this impact and can also improve the working relationship with the participants. To use groups based on more than mere economical and practical standpoints have the potential to create a learning environment in which the participants can become engaged in the activities and be strengthened by the experience. The context of the current study was parent education groups, but the findings are relevant to all instances of groups led by nurses in primary care. The LTA model can be used as a basis for reflection of one's own practice when working with groups in primary care. 


\section{ACKNOWLEDGEMENTS}

Interviews were conducted by the two authors, and Dr Berlin and Dr Barimani (both Karolinska Institutet, Sweden).

\section{FUNDING}

This research was funded by the Swedish Research Council (grant \# 721-2012-5473).

\section{CONFLICT OF INTEREST}

None.

\section{REFERENCES}

Ahldén I, Göransson A, Josefsson A \& Alehagen S (2008) Parenthood education in Swedish antenatal care: perceptions of midwives and obstetricians in charge. The Journal of Perinatal Education 17, 21-27.

Andersson E, Christensson K \& Hildingsson I (2012) Parents' experiences and perceptions of group-based antenatal care in four clinics in Sweden. Midwifery 28, 502-508.

Bandura A (1976) Social learning theory. Pearson, London.

Barlow J, Coe C, Redshaw M \& Underdown, A (2009) Birth and beyond. Stakeholder perceptions of current antenatal education provision in England. Report. National Child and Maternal Health Intelligence Network. Retrieved from:

http://webarchive.nationalarchives.gov.uk/20130107105354/http://www.dh.gov.uk/prod consum dh/groups/dh digitalassets/documents/digitalasset/dh 109831.pdf

Boud D, Cohen R \& Sampson J (Eds.) (2001) Peer learning in higher education. Learning from and with each other. Routledge, London.

Braun V \& Clarke V (2006) Using thematic analysis in psychology. Qualitative Research in Psychology 3, 77-101.

Bryanton J, Beck CT \& Montelpare W (2013) Postnatal parental education for optimizing infant general health and parent-infant relationships. Cochrane Database of Systematic Reviews 2013, Issue 11. Art. No.: CD004068. doi: 10.1002/14651858.CD004068.pub4.

Deave T, Johnson D \& Ingram J (2008) Transition to parenthood: the needs of parents in pregnancy and early parenthood. BMC Pregnancy Childbirth 8, 1-11.

Dornan T, Boshuizen H, King N \& Scherpbier A (2007) Experience-based learning: a model linking the processes and outcomes of medical students' workplace learning. Medical Education 41, 84-91.

Fabian H, Rådestad I \& Waldenström U (2006) Characteristics of primiparous women who are not reached by parental education classes after childbirth in Sweden. Acta Paediatrica 95, 1360-1369.

Gagnon AJ \& Sandall J (2007) Individual or group antenatal education for childbirth or parenthood, or both. Cochrane Database Systematic Reviews 2007, Issue 3. Art. No.: CD002869. doi: 10.1002/14651858.CD002869.pub2.

Gillies RM (2003) Structuring cooperative group work in classrooms. International Journal of Educational Research 39, 35-49.

Hoddinott P, Allan K, Avenell A \& Britten J (2010) Group interventions to improve health outcomes: a framework for their design and delivery. BMC Public Health 10, 1-9.

Jarvis J, Skinner TC, Carey ME \& Davies MJ (2010) How can structured self-management patient education improve outcomes in people with type 2 diabetes? Diabetes, Obesity and Metabolism 12, 12-19.

Kolb D (2014) Experiential Learning. Experience as the source of learning and development. London, Pearson FT Press. 
Lefèvre Å, Lundqvist P, Drevenhorn E \& Hallstrom I (2014) Parents' experiences of parental groups in Swedish child health-care: Do they get what they want? Journal of Child Health Care. doi:10.1177/1367493514544344

Lefèvre Å, Lundqvist P, Drevenhorn E \& Hallström I (2013) Managing parental groups during early childhood: New challenges faced by Swedish child health-care nurses. Journal of Child Health Care. doi:10.1177/1367493513509421

MAXQDA (2014) Qualitative Data Analysis Software. Retrieved at http://www.maxqda.com

Murphy Tighe S (2010) An exploration of the attitudes of attenders and non-attenders towards antenatal education. Midwifery 26, 294-303.

Nolan ML (2009) Information Giving and Education in Pregnancy: A Review of Qualitative Studies. The Journal of Perinatal Education 18(4), 21-30.

Norling-Gustafsson A, Skaghammar K \& Adolfsson A (2011) Expectant parents' experiences of parental education within the antenatal health service. Psychology Research and Behavior Management 4, 159-167.

Petersson K, Petersson C \& Håkansson A (2004) What is good parental education? Interviews with parents who have attended parental education sessions. Scandinavian Journal of Caring Sciences 18, 82-89.

Sahlsten MJM, Larsson IE, Sjöström B \& Plos KAE (2008) An Analysis of the Concept of Patient Participation. Nursing Forum 43, 2-11.

Schrader McMillan A, Barlow J \& Redshaw M (2009) Birth and beyond. A review of the evidence about antenatal education. Report. National Child and Maternal Health Intelligence Network. Retrieved from: http://webarchive.nationalarchives.gov.uk/20130107105354/http://www.dh.gov.uk/prod_c onsum dh/groups/dh digitalassets/documents/digitalasset/dh 109831.pdf

Secomb J (2008) A systematic review of peer teaching and learning in clinical education. Journal of Clinical Nursing 17, 703-716.

Severinsson E, Haruna M \& Friberg F (2010) Midwives' group supervision and the influence of their continuity of care model - a pilot study. Journal of Nursing Management 18, 400-408.

Simons TL \& Peterson RS (2000) Task conflict and relationship conflict in top management teams: The pivotal role of intragroup trust. Journal of Applied Psychology 85, 102-111.

Strauss AS \& Corbin C (1998) Basics of qualitative research. Techniques for developing grounded theory. London, Sage Publications.

Sundelin C \& Håkansson A (2000) The importance of the Child Health Services to the health of children. Acta Paediatrica Supplement 89, 76-79.

Thielen K (2012) Exploring the group prenatal care model: A critical review of the literature. The Journal of Perinatal Education 21, 209-218.

Vygotsky LS (1978) Mind in society. Cambridge, Harvard University Press.

Wiener A \& Rogers C (2008) Antenatal classes: women can't think beyond labour. British Journal of Midwifery 16, 121-124. 